\title{
Efeito residual de herbicidas na cultura do crambe em sucessão ${ }^{1}$
}

\author{
Herbicides carryover effects for the crop Crambe abyssinica in succession
}

\section{Paulo César Timossi ${ }^{2}$; Werley Soares Silva ${ }^{3}$; Suzete Fernandes Lima ${ }^{4}$; Valdiney Ferreira Alves ${ }^{3}$; Dieimisson Paulo Almeida ${ }^{4}$}

Resumo - Herbicidas aplicados em um sistema de produção com cultivos em sucessão podem apresentar efeito residual, na cultura subsequente, causando injúrias na cultura em sucessão. Tal efeito é denominado de carryover, o qual é importante o conhecimento para o planejamento e recomendação de sucessão de culturas. $\mathrm{O}$ trabalho objetivou avaliar o efeito carryover da associação de herbicidas utilizados na dessecação para cultivo de soja, em Crambe abyssinica, cultivar FMS-Brilhante, cultivada em sucessão. O experimento foi instalado e conduzido em delineamento experimental de blocos casualizado, com oito tratamentos e três repetições. Os tratamentos foram: glyphosate (1.300 g e.a. ha $\left.{ }^{-1}\right)$, glyphosate $+2,4-\mathrm{D}(1.300$ g e.a. +1.005 g e.a. $\left.\mathrm{ha}^{-1}\right)$, glyphosate $+($ paraquat + diuron $)\left[1.300\right.$ g e.a. $+\left(600+300\right.$ g i.a. ha $\left.\left.{ }^{-1}\right)\right]$, glyphosate + carfentrazone-ethyl $\left(1.300\right.$ g e.a. +40 g i.a. ha $\left.{ }^{-1}\right)$, glyphosate + saflufenacil $(1.300$ g e.a. $+24,5 \mathrm{~g}$ i.a. ha $\left.^{-1}\right)$, glyphosate + flumioxazyn $\left(1.300\right.$ g e.a. +35 g i.a. ha $\left.{ }^{-1}\right)$, glyphosate + diclosulam $(1.300$ g e.a. +25 g i.a. ha $\left.{ }^{-1}\right)$, glyphosate + chlorimuron-ethyl $\left(1.300\right.$ g e.a. +20 g i.a. ha $\left.{ }^{-1}\right)$. Após a colheita da soja (120 DAS - dias após a semeadura), semeou-se a cultura do crambe. As avaliações basearam-se na determinação da população de plantas (aos 30 DAS), massa seca no florescimento (45 DAS) e determinação de características agronômicas (90 DAS) da cultura do crambe. Concluise que a associação de glyphosate aos herbicidas residuais utilizados no sistema plante e aplique da cultura da soja, não afetaram negativamente a cultura do crambe, em solo de textura argilosa.

Palavras-chaves: mistura em tanque, seletividade, Crambe abyssinica

\begin{abstract}
Herbicides applied in previous crop may present residual effects, causing injuries in the crop in succession. Furthermore, it essential the research of tolerant crops to possible residual effects which is denominated like carryover. The objective of this research was to evaluate the carryover effects of the herbicide associations adopted in the desiccation for the soybean cultivate, in Crambe abyssinica FMS-Brilhante cultivar, grown in succession. The experiment was established and conducted in a completely randomized experimental design, with eight treatments and three replications. Treatments were: glyphosate $\left(1,300 \mathrm{~g}^{\text {a.e. }} \mathrm{ha}^{-1}\right)$, glyphosate $+2,4-\mathrm{D}(1,300$ g a.e. $+1,005$ g a.e. ha $\left.{ }^{-1}\right)$, glyphosate + (paraquat + diuron) $\left[1,300\right.$ g a.e. $+\left(600+300 \mathrm{~g}^{-1}\right.$.i. ha $\left.\left.{ }^{-1}\right)\right]$, glyphosate + carfentrazone-ethyl $\left(1,300\right.$ g a.e. +40 g a.i. ha $\left.{ }^{-1}\right)$, glyphosate + saflufenacil $(1,300 \mathrm{~g}$ a.e. $+24,5$ g a.i. ha $\left.{ }^{-1}\right)$, glyphosate + flumioxazyn $\left(1,300\right.$ g a.e. +35 g a.i. ha $\left.{ }^{-1}\right)$, glyphosate + diclosulam $\left(1,300 \mathrm{~g}\right.$ a.e. $+25 \mathrm{~g}$ a.i. $\left.\mathrm{ha}^{-1}\right)$, glyphosate + chlorimuron-ethyl $(1,300 \mathrm{~g}$ a.e. $+20 \mathrm{~g}$ a.i. $\left.\mathrm{ha}^{-1}\right)$. After soybean harvest, it was sown the crambe crop. The evaluations were based on the

\footnotetext{
${ }^{1}$ Recebido para publicação em 18/10/2013 e aceito em 08/03/2014.

${ }^{2}$ Professor na Universidade Federal de Goiás - Regional Jataí. Rodovia BR 364, km 192, Setor Parque Industrial, 3800, Caixa postal 03, 75801-615, Jatai, GO, Brasil. E-mail para correspondência: ptimossi2004@ yahoo.com.br ${ }^{3}$ Eng. Agr. pela Universidade Federal de Goiás - Regional Jataí.

${ }^{4}$ Eng. Agr. Mestre em Agronomia pelo PPGA - Programa de Pós-Graduação em Agronomia - da Universidade Federal de Goiás - Regional Jataí.
} 
determination of the plants population, at 30 days after sowing, dry biomass at flowering (45 days after sowing). At 90 days after sowing, it was evaluated the agronomic characteristics and yield of the crambe crop. It was concluding that the glyphosate association with the studied herbicides, when adopted in system of "applies and plant" the soybean, has no carryover effects for crambe crop when cultivated on clayey soils.

Keywords: tank mixture, selectivity, Crambe abyssinica

\section{Introdução}

O solo é o destino final dos produtos fitossanitários utilizados na agricultura. Ao se depositarem no solo as moléculas químicas estão sujeitas a reações físico-químicas que regulam seu destino no ambiente. Um dos grandes problemas notados em cultivos em sucessão é a intoxicação de plantas proporcionada por herbicidas que apresentam efeito residual (Greenland, 2003; Soltani et al., 2005; Mancuso et al., 2011). Tal efeito é denominado de carryover, no qual herbicidas que apresentam atividade residual no solo em período superior ao ciclo de vida de uma cultura, pode interferir em cultivos sucessores.

O efeito carryover pode ser influenciado por fatores agronômicos como a espécie da cultura em sucessão, a eficiência da aplicação do herbicida, o herbicida utilizado, atributos físicos e químicos do solo, o sistema de produção, além das condições ambientais após a aplicação (Greenland, 2003; Alonso et al., 2013). Solos com alto teor de argila e matéria orgânica podem favorecer a persistência dos herbicidas no solo. Por outro lado, podem gerar efeitos como sorção e degradação das moléculas. Essa persistência é um fenômeno temporário no qual as moléculas em solução fixam-se a uma superfície sólida, formando forças de interação e, a intensidade dessas forças resulta em alteração da concentração do herbicida na solução do solo (Silva et al., 2009). Outros fatores que interferem na permanência das moléculas de herbicidas no solo estão ligadas a precipitação pluvial, solubilidade dessas moléculas em água, $\mathrm{pH}$, textura do solo, tamanho e distribuição das partículas no solo, densidade do solo e tamanho e distribuição dos poros (Prata et al., 2003).
No intuito de minimizar a reinfestação de plantas daninhas no estabelecimento das culturas, tem sido adotada a associação de herbicidas com efeito residual ao glyphosate no momento da dessecação da vegetação para implantação da cultura, normalmente em sistema de plantio direto (Monquero et al., 2001; Vidrine et al., 2002; Procópio et al., 2007). Assim, em regiões onde há possibilidade de cultivo de duas safras em um mesmo ano agrícola, o efeito carryover dos herbicidas pode tornar-se mais evidente.

Dentre as culturas com potencial para o cultivo em segunda safra e rotação de culturas, na região Centro-Oeste do Brasil, têm-se a espécie Crambe abyssinica. O crambe pertence à família Brassicaceae, com ciclo curto variando de 85 a 100 dias (Oplinger et al., 2008) e frutos do tipo síliqua (Desai et al., 1997). No Brasil, a espécie tem sido pesquisada e divulgada para a produção de biodiesel, por possuir elevado teor de óleo em suas sementes, que pode chegar até $38 \%$ (Pitol et al., 2010).

Para a cultura de crambe são raras as pesquisas que indicam herbicidas para o manejo das plantas daninhas. No Brasil, não existe se quer herbicidas registrados para a cultura do crambe. Entretanto, de acordo com Oliveira Neto et al. (2011), há possibilidade de utilização de herbicidas em aplicação de pré-emergência como trifluralin, pendimethalin e alachlor, além de herbicidas graminicidas em pós-emergência. No entanto, quanto ao efeito carryover de herbicidas na cultura de crambe, ainda não há informações disponíveis para as condições brasileiras.

Neste contexto, objetivou-se avaliar o efeito carryover da associação de herbicidas residuais ao glyphosate, utilizados na 
dessecação da vegetação espontânea para cultura da soja, na cultura de Crambe abyssinica, cultivar FMS-Brilhante, cultivada em sucessão.

\section{Material e Métodos}

A pesquisa foi conduzida na Fazenda Santa Rosa do Rochedo da Universidade Federal de Goiás - Regional Jataí, nas seguintes coordenadas: S $17^{\circ} 55^{\prime} 465^{\prime \prime}$ e WO 51 ${ }^{\circ} 42^{\prime}$ ' 826".
A região apresenta altitude de cerca de $680 \mathrm{~m}$ e precipitação pluvial anual entre 1650 a 1800 $\mathrm{mm}$, distribuída entre os meses de setembro a abril, com temperatura do ar média em torno de $25^{\circ} \mathrm{C}$ (Mariano \& Scopel, 2001). O solo do local é caracterizado como Latossolo Vermelho distroférrico, com relevo suave, boa drenagem e textura argilosa (Embrapa, 2006). Os dados climatológicos relativos ao período de condução da pesquisa são representados na Figura 1.

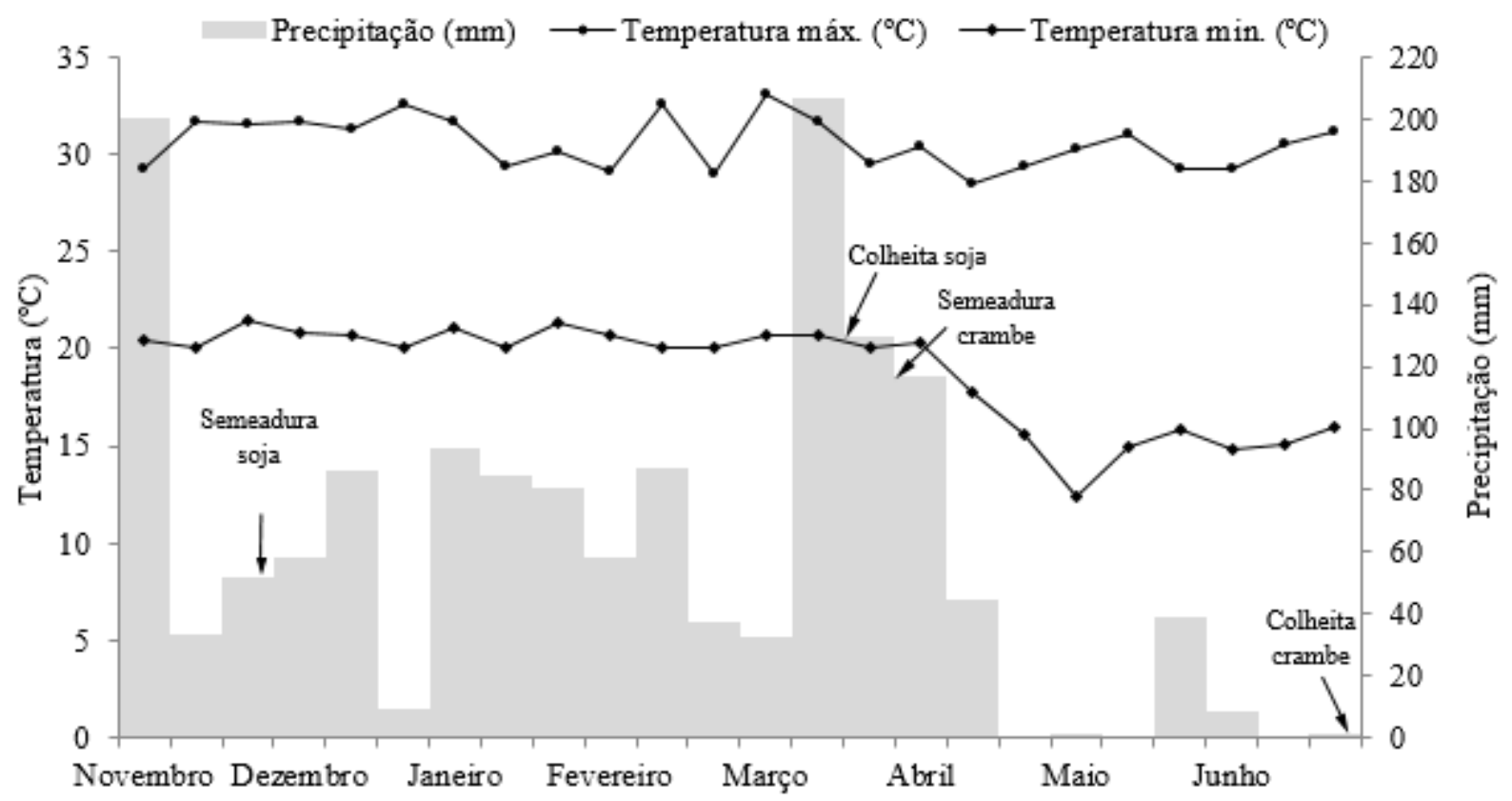

Figura 1. Médias de temperatura máxima e mínima do ar e total de precipitações pluviais, em decêndios, durante o período de condução do experimento, obtidos na estação meteorológica do Instituto Nacional de Meteorologia - INMET, localizada a 1,2 km do campo experimental.

O delineamento experimental utilizado foi $\mathrm{o}$ de blocos casualizados, com oito tratamentos e três repetições. As parcelas apresentaram 3,0 $\mathrm{m}$ de largura por $8,0 \mathrm{~m}$ de comprimento, totalizando $24 \mathrm{~m}^{2}$, nas quais foram semeadas cinco linhas da cultura de crambe, espaçadas em $0,45 \mathrm{~m}$. As sementes adotadas na pesquisa foram provenientes da concessão/doação realizada pela empresa Caramuru Alimentos S/A, à qual possui parceria com a Fundação MS, detentora do material genético.
A pesquisa se iniciou no período da safra 2012-13, com a semeadura da soja realizada em 24/11/2012, na qual se adotou a dessecação da vegetação espontânea pelo sistema "plante e aplique", no intuito de evitar a contaminação de parcelas consecutivas no ato da realização da semeadura da cultura. Portanto, a aplicação dos tratamentos para a dessecação foi realizada no mesmo dia da semeadura da soja.

A caracterização física e química do solo amostrado é apresentada na Tabela 1. Os tratamentos herbicidas e suas respectivas doses são representados na Tabela 2. Salienta-se que o 
tratamento testemunha foi representado pela aplicação de glyphosate isolado, ou seja, sem efeito residual, pois o sistema de cultivo utilizado foi o plantio direto, o qual necessita de manejo químico da vegetação para posterior implantação da cultura.

Para a aplicação dos herbicidas foi utilizado pulverizador de pesquisa, pressurizado por $\mathrm{CO}_{2}$ em pressão constante de 2 bar, com barra de seis bicos e pontas TT110.015, com volume de aplicação de $120 \mathrm{~L} \mathrm{ha}^{-1}$. Durante a aplicação dos herbicidas, foram registradas as condições climatológicas, as quais encontramse representadas na Tabela 3.

Tabela 1. Propriedades físicas e químicas da amostra de solo da área experimental.

\begin{tabular}{|c|c|c|c|c|c|c|c|c|c|c|c|}
\hline $\mathrm{pH}$ & $\mathrm{Al}$ & $\mathrm{Ca}$ & $\mathrm{Mg}$ & CTC & $\mathrm{K}$ & $\mathrm{P}$ & V & MO & Areia & Silte & Argila \\
\hline $\mathrm{H}_{2} \mathrm{O}$ & \multicolumn{4}{|c|}{$\left(\mathrm{cmol}_{\mathrm{c}} \mathrm{dm}^{-3}\right)$} & \multicolumn{2}{|c|}{$\left(\mathrm{mg} \mathrm{dm}^{-3}\right)$} & $(\%)$ & $\left(\mathrm{g} \mathrm{dm}^{-3}\right)$ & \multicolumn{3}{|c|}{$(\%)$} \\
\hline $5,8^{*}$ & 0,3 & 2,2 & 1,0 & 9,1 & 119,1 & 4,9 & 38,8 & 35,2 & 17,2 & 40,8 & 42 \\
\hline
\end{tabular}

*Determinações realizadas pelo Laboratório de Análise de Solos da UFG- Regional Jataí - GO.

Tabela 2. Descrição dos tratamentos com herbicidas e respectivas doses utilizadas na dessecação, no sistema "plante e aplique", para o cultivo da cultura da soja.

\begin{tabular}{llc}
\hline \multicolumn{1}{c}{ Tratamentos } & \multicolumn{1}{c}{ Herbicidas } & Dose (g e.a. ou i.a. ha ${ }^{-1}$ ) \\
\hline 1 & glyphosate & 1.300 \\
2 & glyphosate + 2,4-D & $1.300+1.005$ \\
3 & glyphosate + (paraquat + diuron) & $1.300+600+300$ \\
4 & glyphosate + carfentrazone-ethyl & $1.300+40$ \\
5 & glyphosate + saflufenacil & $1.300+24,5$ \\
6 & glyphosate + flumioxazyn & $1.300+35$ \\
7 & glyphosate + diclosulam & $1.300+25$ \\
8 & glyphosate + chlorimuron-ethyl & $1.300+20$ \\
\hline
\end{tabular}

Tabela 3. Condições climatológicas referentes ao momento da aplicação dos herbicidas.

\begin{tabular}{lcccccccc}
\hline \multirow{2}{*}{ Data } & $\mathrm{T}^{1}$ & $\mathrm{~T}^{2}$ & $\mathrm{UR}^{1}$ & $\mathrm{UR}^{2}$ & $\mathrm{HA}^{1}$ & $\mathrm{HA}^{2}$ & $\mathrm{VV}$ & $\mathrm{CN}$ \\
$(\%)$ & $\left({ }^{\circ} \mathrm{C}\right)$ & $\left({ }^{\circ} \mathrm{C}\right)$ & $(\%)$ & $(\%)$ & $(\mathrm{h})$ & $(\mathrm{h})$ & $(\mathrm{m} / \mathrm{s})$ & $\begin{array}{c}(\%) \\
24 / 11 / 2012\end{array}$ \\
\hline 25,7 & 27,1 & 88 & 77 & $10: 35$ & $11: 50$ & 2 & 100 \\
\hline
\end{tabular}

Temperatura (T), Umidade Relativa (UR), Horário de Aplicação (HA), Velocidade do Vento (VV), Cobertura de Nuvens $(\mathrm{CN}){ }^{(1)}$ Inicial, ${ }^{(2)}$ Final.

Após a colheita mecanizada da soja, aos 120 dias após a aplicação (DAA) dos herbicidas, semeou-se a cultura do crambe (02/04/2013), com semeadora mecanizada em plantio direto. Aos 30 dias após a semeadura (DAS) foi determinada a população de plantas de crambe em todos os tratamentos através da contagem do número de plantas normais emergidas, em três linhas centrais das parcelas, totalizando 7,5 m.

No florescimento, aos 45 DAS, determinou-se o acúmulo de massa seca da parte aérea das plantas de crambe, coletada em $1 \mathrm{~m}$ dentro da área útil da parcela. As plantas foram cortadas rente ao solo e levadas para secagem em câmara de circulação forçada de ar a $70{ }^{\circ} \mathrm{C}$, mantida até peso constante, seguido de determinação do peso de massa seca.

No período da colheita, aos 90 DAS, foram avaliadas as características agronômicas de altura de plantas, peso de 1.000 síliquas e produtividade de síliquas $\left(\mathrm{kg} \mathrm{ha}^{-1}\right)$. Para isto foram coletadas plantas de crambe nas três linhas centrais, com $6 \mathrm{~m}$ de comprimento, para determinação das características produtivas; onde também se determinou a altura em dez plantas tomadas ao acaso, medindo-se o comprimento entre o colo das plantas até o ápice da haste principal. 
Os dados obtidos foram submetidos à análise de variância e suas médias comparadas pelo teste de Tukey a 5\% (Banzato \& Kronka, 1989).

\section{Resultados e Discussão}

Os dados de população de plantas por hectare da cultura do crambe, submetidas aos tratamentos encontram-se representado na Figura 2.

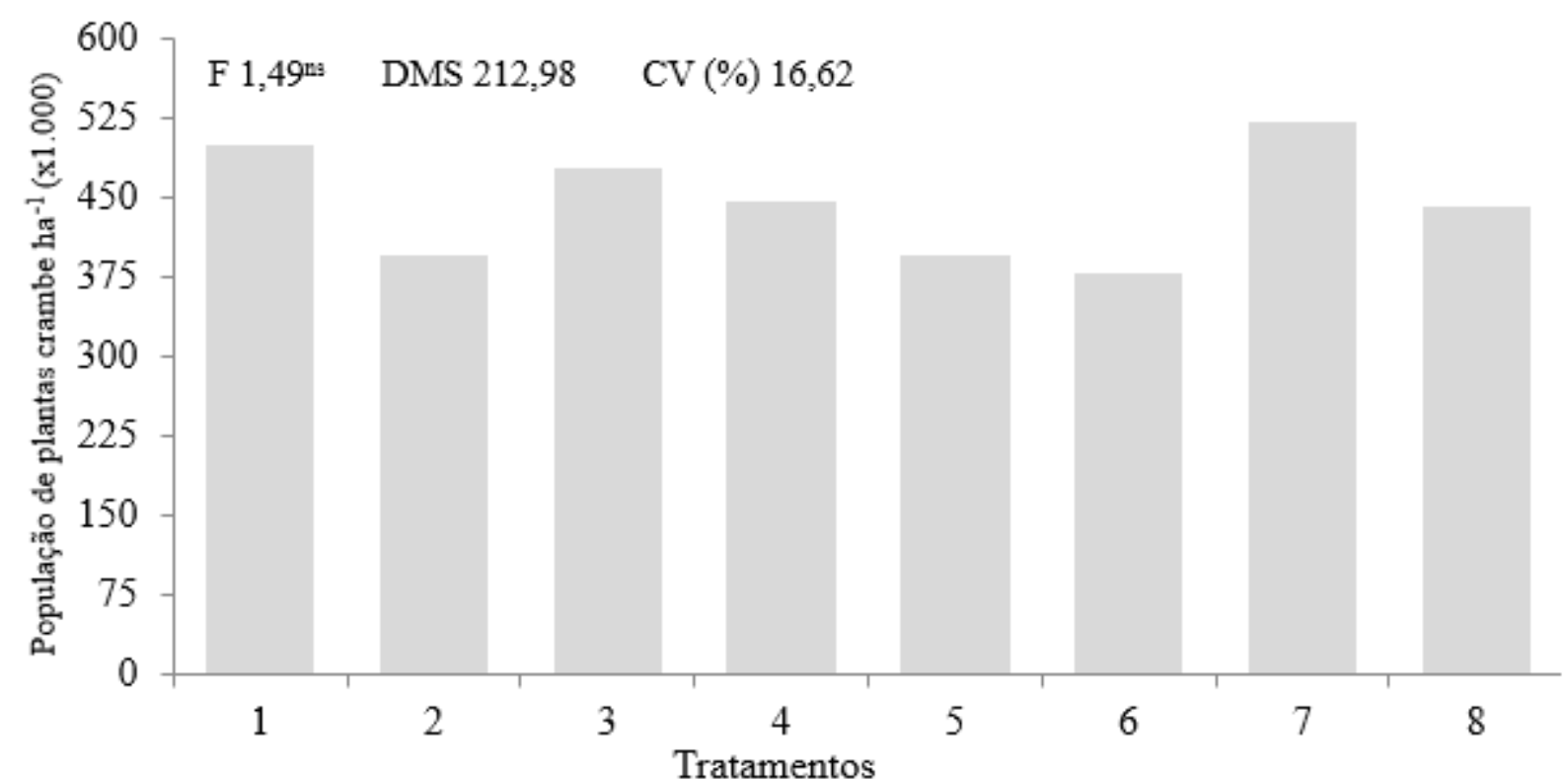

Figura 2. População de plantas de crambe (plantas ha- ${ }^{-1}$ ), aos 30 dias após a semeadura, em função dos tratamentos: 1. glyphosate; 2. glyphosate + 2,4-D; 3. glyphosate + (paraquat + diuron); 4 . glyphosate + carfentrazone-ethyl; 5. glyphosate + saflufenacil; 6. glyphosate + flumioxazyn; 7 . glyphosate + diclosulam; 8. glyphosate + chlorimuron-ethyl.

Nota-se que não há diferença entre a testemunha (glyphosate) e as associações de herbicidas com efeito residual, caracterizando que a semeadura do crambe aos 120 DAA dos herbicidas não sofreu interferência negativa nessa variável. Esse fato é de grande relevância, já que a população de plantas é um ponto fundamental para obtenção de alta produtividade das culturas. Desta forma, a cultura do crambe torna-se mais uma opção a ser cultivada em segunda safra, para áreas onde foram utilizadas as associações dos herbicidas na cultura da soja. De acordo com Oliveira Júnior (2002), o planejamento da rotação de culturas deve ser criterioso para evitar o efeito carryover. Oliveira Neto et al. (2011) afirmaram que para o herbicida trifluralin nas dosagens de 0,5 e $1,0 \mathrm{~L} \mathrm{ha}^{-1}$ apresenta potencial seletivo para a oleaginosa estudada, porém com dose de 1,5 e 2,0 $\mathrm{L} \mathrm{ha}^{-1}$ ocasionou níveis de fitointoxicação intermediário. Assim, nota-se a importância da realização de trabalhos científicos com herbicidas para a cultura do crambe, considerando as dosagens a serem administradas.

Oliveira Júnior (2001) pesquisando o efeito residual de imazaquin e alachlor + atrazine para plantio sequencial de canola, constatou que a semeadura da canola pode ser realizada 90 DAA destes herbicidas, sem que haja prejuízos na emergência e desenvolvimento da cultura por efeito carryover. Maiores intervalos de tempo entre a aplicação dos herbicidas e o cultivo da cultura em sucessão tende a reduzir os efeitos de fitointoxicação nas plantas. 
O acúmulo de massa seca de plantas da cultura do crambe, determinado aos 45 DAS, encontra-se representado na Figura 3.

Constatou-se que os herbicidas não apresentaram efeito residual para a cultura do crambe após a colheita da soja, uma vez que não apresentaram diferenças entre as médias de massa seca. Assim, o resíduo apresentado pelos herbicidas não promoveu alterações detectadas na massa seca de plantas de crambe. Entretanto, foi constatada grande variação no desenvolvimento das plantas, o que elevou o valor da diferença mínima significativa $(547,20)$, apesar de não ter sido constatada diferenças singificativas entre os tratamentos. Em parte, essa variação no desenvolvimento das plantas pode ser explicada pela rusticidade das plantas, as quais ainda se encontram processo de domesticação, além da baixa disponibilidade hídrica durante o ciclo da cultura do crambe.

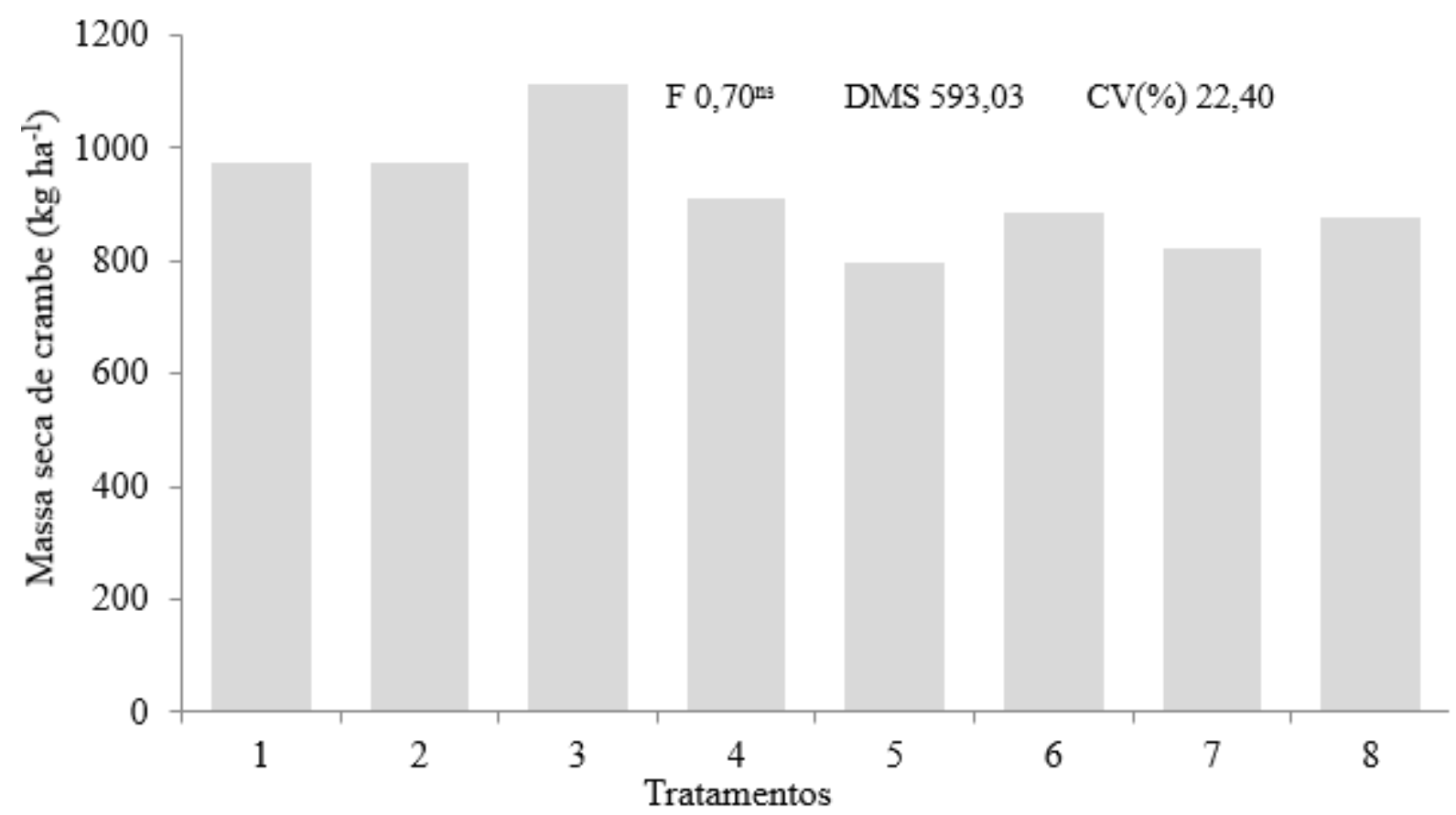

Figura 3. Massa seca de plantas de crambe $\left(\mathrm{kg} \mathrm{ha}^{-1}\right)$, aos 45 dias após a semeadura, em função dos tratamentos: 1. glyphosate; 2. glyphosate + 2,4-D; 3. glyphosate + (paraquat + diuron); 4. glyphosate + carfentrazone-ethyl; 5. glyphosate + saflufenacil; 6. glyphosate + flumioxazyn; 7. glyphosate + diclosulam; 8. glyphosate + chlorimuron-ethyl.

Alves et al. (2012) constataram que os herbicidas diuron, trifularin e haloxyfop-pmethyl não interferiram na quantidade de biomassa produzida pela cultura do crambe. Resultado diferente foi encontrado pelos mesmos autores para os herbicidas nicosulfuron e tembotrione que retardaram o desenvolvimento das plantas, interferindo no acúmulo de massa seca e, consequentemente, caracterizando como não seletivos para a cultura do crambe.
As características agronômicas: altura de plantas, peso de 1.000 síliquas e produtividade de síliquas $\left(\mathrm{kg} \mathrm{ha}^{-1}\right)$ encontra-se na Tabela 4 . Constata-se que as associações de herbicidas não diferem da testemunha (glyphosate), a qual pode ser explicada devido à irregularidade na disponibilidade hídrica relacionada à época de semeadura da cultura do crambe, a qual foi realizada no limíte da recomendação técnica (Pitol et al., 2010). A produtividade de síliquas obtida foi considerada baixa quando comparada às médias obtidas em campos de produção, as 
quais variam, segundo Pitol et al. (2010), de 500 a $1.500 \mathrm{~kg} \mathrm{ha}^{-1}$.

Além da possibilidade de ocorrência de sorção e degradação por microorganismos, outro fator que interfere na permanência das moléculas de herbicida no solo está ligada a precipitação pluvial em conjunto com a solubilidade dos herbicidas em água, acarretando na lixiviação, e percolação no perfil do solo, podendo até contaminar os lençois freáticos. No período de condução do trabalho, o acúmulo da precipitação pluvial referente à aplicação dos herbicidas na cultura da soja até a semeadura do crambe (120 dias) foi de 1.051 $\mathrm{mm}$, o que pode ter contribuído para não ocorrência de carryover na cultura de crambe, cultivada em sucessão.

Tabela 4. Altura de plantas, peso de 1.000 síliquas e produtividade de síliquas em função dos herbicidas estudados.

\begin{tabular}{lccc}
\hline Tratamentos & $\begin{array}{c}\text { Altura de plantas } \\
(\mathrm{cm})\end{array}$ & $\begin{array}{c}\text { Peso de 1.000 } \\
\text { Síliquas } \\
(\mathrm{g})\end{array}$ & $\begin{array}{c}\text { Produtividade de } \\
\text { Síliquas } \\
\left(\mathrm{kg} \mathrm{ha}^{-1}\right)\end{array}$ \\
\hline Glyphosate & $80,90 \mathrm{a}^{1}$ & $6,98 \mathrm{a}$ & $588,20 \mathrm{a}$ \\
Glyphosate + 2,4-D & $80,12 \mathrm{a}$ & $7,34 \mathrm{a}$ & $467,60 \mathrm{a}$ \\
Glyphosate + (paraquat + diuron) & $78,52 \mathrm{a}$ & $7,43 \mathrm{a}$ & $441,50 \mathrm{a}$ \\
Glyphosate + carfentrazone-ethyl & $76,26 \mathrm{a}$ & $7,15 \mathrm{a}$ & $435,80 \mathrm{a}$ \\
Glyphosate + saflufenacil & $76,12 \mathrm{a}$ & $7,29 \mathrm{a}$ & $429,50 \mathrm{a}$ \\
Glyphosate + flumioxazyn & $75,10 \mathrm{a}$ & $7,26 \mathrm{a}$ & $383,70 \mathrm{a}$ \\
Glyphosate + diclosulam & $76,38 \mathrm{a}$ & $7,19 \mathrm{a}$ & $427,40 \mathrm{a}$ \\
Glyphosate + chlorimuron-ethyl & $75,32 \mathrm{a}$ & $7,10 \mathrm{a}$ & $424,70 \mathrm{a}$ \\
\hline F & $0,28^{\mathrm{ns}}$ & $0,40^{\mathrm{ns}}$ & $1,22^{\mathrm{ns}}$ \\
DMS & 19,49 & 1,03 & 273,61 \\
CV $\%)$ & 12,19 & 6,93 & 21,11 \\
\hline
\end{tabular}

${ }^{1}$ Medias seguidas pela mesma letra, na mesma coluna, não diferem entre si, pelo teste de tukey a 5\% de probabilidade $(\mathrm{p} \leq 0,05)$.

\section{Conclusões}

A associação dos herbicidas residuais ao glyphosate não apresentaram efeito carryover para a cultura do crambe, quando cultivados em sucessão à cultura da soja cultivada em solos de textura argilosa.

\section{Referências}

ALONSO, D.G.; OLIVEIRA JÚNIOR, R.S.; CONSTANTIN, J. Potencial de carryover de herbicidas com atividade residual usados em manejo outonal. In: CONSTANTIN, J.; OLIVEIRA JÚNIOR, R.S.; OLIVEIRA NETO, A.M. (Ed.). Buva: Fundamentos e recomendações para manejo. Curitiba: Omnipax, 2013, cap.08, p.91-104.

ALVES, V.F. et al. Seletividade de herbicidas aplicados em pré e pós-emergência na cultura do crambe. In: CONGRESSO DE PESQUISA, ENSINO E EXTENSÃO - CONPEEX, 9., 2012, Goiânia. Anais... Goiânia: UFG, 2012. p. 8635-8645.

BANZATO, D.A.; KRONKA, S.N. Experimentação Agrícola, Jaboticabal: FUNEP, 1989. 247p.

DESAI, B.B.; KOTECHA, P.M. SALUNKE, D.K. Seeds handbook biology, production, processing and storage. 1 ed. New York: Basel, 1997, 627p.

EMBRAPA. Centro Nacional de Pesquisa de Solos. Sistema brasileiro de classificação de solos. 2. ed. Rio de Janeiro, 2006. 306 p.

GREENLAND, R. Injury to vegetable crops from herbicides applied in previous years. Weed Technology, v.17, n.1, p.73-78, 2003. 
MANCUSO, M.A.C.; NERGRISOLI, E.; PERIM, L. Efeito residual de herbicidas no solo ("Carryover"). Revista Brasileira de Herbicidas, v.10, n.2, p.151-164, 2011.

MARIANO, Z.F.; SCOPEL, I. Períodos de deficiências e excedentes hídricos na região de Jataí-GO. In: CONGRESSO BRASILEIRODE AGROMETEOROLOGIA, 12., 2001, Fortaleza. Anais... Fortaleza: SBA, 2001. p.333-334.

MONQUERO, P.A.; CHRISTOFFOLETI, P.J.; SANTOS, C.T.D. Glyphosate em mistura com herbicidas alternativos para o manejo de plantas daninhas. Planta Daninha, v.19, n.3, p.375380, 2001.

OLIVEIRA JÚNIOR, R.S. Atividade residual de imazaquin e alachlor+atrazina para plantio sequencial de canola. Ciência Rural, v.31, n.2, p.219-224, 2001.

OLIVEIRA JÚNIOR, R.S. Conceitos importantes no estudo do comportamento de herbicidas no solo. Boletim informativo Sociedade Brasileira de Ciência do Solo, v.27, n.2, p.9-12, 2002.

OLIVEIRA NETO, A.M. et al. Seletividade de herbicidas utilizados em pré-emergência na cultura do crambe. Revista Brasileira de Herbicidas, v.10, n.1, p.49-56, 2011.

OPLINGER, E. S. et al. Crambe. Alternative Field Crop Manual, 2008. Disponível em: $<$ http://www.hort.purdue.edu/newcrop/afcm/cr ambe.html>. Acesso em: 25 abril 2013.

PITOL, C.; BROCH, D. L.; ROSCOE, R. Tecnologia e produção: Crambe. Maracaju: Fundação MS, 2010. 60 p.

PRATA, F. et al. Glyphosate sorption and desorption in soils with distinct phosphorus levels. Scientia Agricola, v.60, n.1, p.175-180, 2003.

PROCÓPIO, S.O. et al. Utilização de chlorimuron-ethyl e imazethapyr na cultura da soja Roundup Ready ${ }^{\circledR}$. Planta Daninha, v.25, n.2, p.365-373, 2007.

SOLTANI, N.; SIKKEMA, P.H.; ROBINSON, D.E. Vegetable crop responses to chlorimuronethyl applied in the previous year. Crop Protection, v.24, n.7, p.685-688, 2005.

VIDRINE, R.P.; GRIFFIN, J.L.; BLOUIN, D.C. Evaluation of reduced rates of glyphosate and chlorimuron in glyphosate-resistant soybean (Glycine max). Weed Technology, v.16, n.4, p.731-736, 2002. 